\title{
THE LEGACY OF THE STRUVES FOR THE ESTABLISHMENT OF AN INERTIAL COORDINATE SYSTEM ON THE SKY
}

\author{
Alan H. Batten \\ Dominion Astrophysical Observatory \\ Herzberg Institute of Astrophysics \\ Victoria, B.C. \\ Canada
}

\begin{abstract}
Contributions made by Vassily Yakovlevich Struve and his son Otto Vassilyevich to the eventual establishment of an inertial frame of reference on the sky are discussed under five heads: (i) the foundation of Pulkovo Observatory, (ii) instrumentation, (iii) Vassily Yakovlevich's determination of the constant of aberration, (iv) Otto Vassilyevich's determination of the coefficient of precession and (v) international cooperation.
\end{abstract}

\section{Prologue}

Just over 125 years ago, Pulkovo Observatory celebrated its first great jubilee - its twenty-fifth anniversary. Astronomers came from many countries on that occasion, as they have done today, and they assembled in the main rotunda of the Observatory. To inaugurate the proceedings, a frail old man came into the rotunda, supported on the arm of his eldest surviving son. The two walked slowly round the circle of distinguished visitors, greeting each one by name, for they were all personal friends. The old man, of course, was the founding director of the Observatory, usually known in other countries as Wilhelm Struve, but often called in this, his adopted country, Vassily Yakovlevich. This little vignette was drawn for us, not by his eldest son, Otto Vassilyevich, who was also his successor as director, but, rather, by Vassily Yakovlevich's youngest son, Nikolai, who wrote a family history (Struve 1915).

We cannot be privileged on this occasion to be greeted by the founder of this Observatory, but we are in many ways more privileged than those predecessors of ours. Despite our constant complaints about funding, we can bring resources to the study of astronomy beyond their wildest dreams. Travel to gatherings such as this - a rare privilege for most of them - many of us assume to be almost a right. In real terms, travel is probably still cheaper for us than it was for them; it is certainly faster and more convenient. In 1864, the railway from Berlin to St. Petersburg was still incomplete; everyone present at that earlier celebration had made at least part of the journey either by sea or by horse-drawn vehicles. Recalling this fact can help us to feel the poignancy of the occasion. Six years earlier Vassily Yakovlevich had been ravaged by an illness that left him both physically and mentally frail. Friends and colleagues who had looked to him as one of the foremost of their number must have been saddened to see his reduced state. They could not guess that in a little over three months' time he would be dead, but they surely knew that most of them would never see him again. 
Vassily Yakovlevich and his son dominated Pulkovo for one-third the total span that we are now celebrating. They were masters of fundamental astronomy and, in one sense, all their work was a legacy for the establishment of an inertial coordinate system. I am tempted to range widely, or perhaps to concentrate on that aspect of their work that I understand best - the study of double stars. Either course would take too long, however, and would in a large measure repeat what I have recently written (Batten 1988). I shall concentrate, therefore, on five topics (as identified in the Abstract) and, even on these, I must be brief and omit much detail.

\section{The founding of Pulkovo}

By 1830 , it was obvious that the old observatory of the Academy of Sciences, built in the centre of St. Petersburg towards the end of Peter the Great's reign, was no longer adequate. The Academy talked of replacing the old building and instruments, and had even engaged in inconclusive negotiations for a site north of the city, but they lacked both funds and an astronomer of sufficient calibre and dynamism to carry out the project. At the end of 1830, Tsar Nicholas I received Vassily Yakovlevich in audience and, as a result of this meeting, both the Academy's wants were supplied.

Nicholas was not an easy man to love, either in his life or viewed in the retrospective of history, but given the system of autocracy by which imperial Russia was ruled, the building of a new national observatory would have been impossible without the support of the Tsar, and Nicholas appears to have given that support whole-heartedly. Without either of these men, Nicholas or Vassily Yakovlevich, a new observatory probably would have been built sometime in the middle of the nineteenth century, but both of them together were essential for the creation of the "astronomical capital of the world". One provided the money and the political will, the other the scientific abilities and vision. According to Vassily Yakovlevich (Struve 1845), Nicholas himself suggested Pulkovo as the site. Cleveland Abbe (1867), however, who visited Pulkovo shortly after Vassily Yakovlevich's death and talked often with Otto, reports that the elder Struve had a premonition as early as 1828 that the new St. Petersburg Observatory would one day be built there. Perhaps Pulkovo was a rather obvious site, or perhaps Vassily Yakovlevich knew well that the best method of getting your own way is to let your superiors think that it is theirs! It seems likely that there was a mutual respect between the two men, despite the gulf that then separated autocrat and subject, and this was one of the secrets of the successful creation of the new Observatory.

Nicholas, for his part, had two motives for the foundation of Pulkovo. First, the vast lands of the Russian empire needed to be surveyed: the new Observatory was to meet precisely the same sort of practical need as those founded earlier by the world's maritime and colonial powers. Vassily Yakovlevich's success in surveying the arc of the meridian through Dorpat undoubtedly was one reason why he was entrusted with the building of Pulkovo. Nicholas's other motive was quite simply national prestige. At that 1830 audience, the Tsar declared (Struve 1845) that “... l'honneur du pays Lui paraissait réclamer la fondation, près de la capitale, d'un nouvel Observatoire astronomique, conforme à la hauteur actuelle de la science et propre à contribuer à son avancement ultérieur." Those were the motives that loosened the purse strings, but it was the genius and energy of Vassily Yakovlevich that transformed Pulkovo into an observatory destined to make major contributions to the establishment of an inertial coordinate system. 


\section{The instruments}

Instruments are the most important part of an observatory. No matter how good the location, how fine the buildings or how skilled the astronomers, without good instruments all would be wasted. Precisely in the provision of instruments, Nicholas was most ready to trust Vassily Yakovlevich. Cost was to be no consideration, provided only that the instruments were the best available. The trust was well founded. As a youth, Vassily Yakovlevich had installed, without help or supervision, a Dollond transit instrument that had lain several years in its case. Later, when what was then the world's largest refracting telescope was delivered in 22 cases to Dorpat, he discovered that "the maker had forgotten to send the direction" for assembling it (Struve 1826). The maker himself (Fraunhofer) later expressed surprise at the success with which Vassily Yakovlevich assembled the telescope without detailed instructions.

The Dorpat refractor had been bought from Fraunhofer because that was what he had available. Fortified by more than a decade of experience with that refractor, and by the Tsar's carte blanche, Vassily Yakovlevich determined that this time he would tell the instrument makers what he wanted. It has been said that he told them not even a single screw in the designs was to be altered without his consent. Certainly he had a very large say even in details of design. This can be illustrated by the prime-vertical circle, built by the Repsold brothers, and in some respects Vassily Yakovlevich's favourite among the Pulkovo instruments. He credits his friend Bessel with first pointing out that prime-vertical instruments could be used most advantageously for observations near the zenith. His own use of such an instrument in Dorpat, however, convinced Vassily Yakovlevich that it could be the most powerful means of studying aberration, nutation and annual parallax, provided certain changes were made. "Il fallait placer le tube à l'extremité de l'axe de rotation, pour avoir le niveau dans un emplacement permanent sur l' axe....Le second point essentiel était de joindre a l'instrument un appareil propre pour un renversement aussi prompte que possible..." (Struve 1845). The Repsolds succeeded in realizing these ideas. The prime-vertical instrument, we are told, could be reversed in 16 seconds and the astronomer could resume observing on either side of the pier, one minute and twenty seconds after he had finished on the other. Not everyone thought the instrument perfect; Airy (1848) has left his criticisms. Another early visitor to Pulkovo, the American astronomer G.P. Bond, wrote in his diary, however, "Tenths of a second of arc take the position here that seconds have hitherto done elsewhere." (Holden 1897).

Quantum leaps in precision, such as Bond recorded, often lead to great progress in astronomy. For example, the development of the photomultiplier tube was what gave photoelectric photometry its precision and therefore its value for astrophysical research (Wood 1989). Similarly, new techniques for the determination of radial-velocities (Campbell 1983) are now leading to a significant increase in the precision with which at least some velocities can be determined and make it look likely that, if we ever do detect other planetary systems, it will be from their radial, rather than transverse, motions. We are on the threshold of another quantum leap in astrometric precision, that we hope will come from observations made above the Earth's atmosphere. I am sure we shall hear much about this in the next few days. The Struves, however unconsciously, set us on that road by what they did here in Pulkovo; in this, as in so much else, we are their heirs. 


\section{The constant of aberration}

Vassily Yakovlevich began to work on the determination of all the important astronomical constants - aberration, nutation, precession, solar motion etc. - before ever he came to Pulkovo. As we have just seen, his early experience led him to design the prime-vertical instrument explicitly for the determination of the constants of aberration and nutation. Most of the astronomers initially employed at Pulkovo came from Dorpat and were already engaged in the Observatory programme for the determination of these important constants. At Pulkovo, Vassily Yakovlevich took responsibility himself for the determination of the constant of aberration, assigning that of the coefficient of precession to his son, and of the constant of nutation to C.A.F. Peters. The results eventually appeared in three major memoirs (Struve 1841, Struve 1843a, Peters 1844) of which Vassily Yakovlevich wrote: "Les trois mémoires, celui de mon fils sur la précession et le mouvement du système solaire, celui de M. Peters, sur la nutation et le mien surl'aberration, forment un corps entier, qui nous a fourni des fondements nouveaux et incomparablement plus exacts pour les réductions des observations astronomiques, fondements qui étaient indispensables pour faire marcher les travaux de l'observatoire centrale d'une manière digne de ses moyens supérieurs." (Struve 1843b).

Vassily Yakovlevich chose seven stars for observation with the new prime-vertical instrument, primarily for the determination of the constant of aberration, although the observations were continued and later used by Nyrén (1883) for revisions of both that constant and the constant of nutation. All seven stars culminated very close to the zenith. In fact, one can almost deduce the latitude of Pulkovo from the stars chosen. Precessed back to 1850.0, the mean of the declinations of the seven stars is $59^{\circ} 08: 9$, while the value that Vassily Yakovlevich himself adopted for the latitude was $59^{\circ} 46: 3$. For the aberration constant he deduced 20.4451 , with a probable error of about 0:01. This is within 0.3 percent of the currently accepted I.A.U. (1976) value (Astronomical Almanac 1989). It was long accepted as standard, although Nyrén's higher value of 20:517 tended to replace it towards the end of the century. S.C. Chandler (1891b), however, wrote "... I desire to state my strong impression that, although the tendency at present among astronomers is to supplant Struve's constant of aberration by Nyrén's, the lower value will very likely prove to be nearer the true one." In fact, Nyrén's value was an improvement, but also an over-correction.

I have quoted elsewhere Airy's (1848) appreciation of Vassily Yakovlevich's observing skills. Though the style may strike us as pompous, I believe that the tribute was sincere: "I had the pleasure twice of witnessing complete observations made by him [Struve]; and I trust that he will not be offended by the testimony of one who, though a younger man, is not without experience as an observer, to the caution, the delicacy, the steadily waiting to the proper time, the promptitude at the proper time, which distinguish Mr. Struve's observations." A greater tribute, however, is perhaps that these same observations later revealed an effect of which Vassily Yakovlevich had no inkling — the polar wobble detected by Chandler (1891a), with its approximate period of 427 days. Chandler (1893a) later found that if the wobble was taken into account in the analysis of Vassily Yakovlevich's observations, the constant of aberration was 20"481 (plus some small indeterminate terms) and could not, in Chandler's opinion, exceed 20:5. Nyren's determination, on the other hand, was hardly affected when polar wobble was taken into account (Chandler 1893b). Chandler (1891c) also found evidence for the wobble in Bradley's discovery observations. Vassily Yakovlevich, who seems to have regarded Bradley as a model, would, I believe, have been especially gratified by this evidence that his own work was on a par with Bradley's. 


\section{The coefficient of precession}

The coefficient of precession was determined by Otto Vassilyevich (Struve 1841) and, nine years later, his work won him the Gold Medal of the Royal Astronomical Society. I cannot resist quoting Airy's (1850) own explanation of the delay: "This has arisen partly from the delay which usually occurs in the printing and distribution of foreign memoirs; partly from the time which is necessary for thoroughly reading a paper of such length; but principally from the occupation of the minds of astronomers, as well within as without the Society, by the remarkable planetary discoveries made in several years past."

The determination of the coeffcient of precession did not intimately involve one particular instrument in the same way that that of the constant of aberration had. Otto Vassilyevich's method was to compare modern positions (many determined at Dorpat by his father) of 400 stars with the positions determined by Bradley some 70 years earlier. It was natural, indeed inevitable, that, along with the constant of precession, Otto Vassilyevich should also attempt to derive the magnitude and direction of the solar motion. His treatment of the individual proper motions was painstakingly meticulous and he derived a value of 50".235 per annum for the coefficient of general precession. This differs from the I.A.U. 1976 value by little more than 0.1 percent. I am indebted to one of our cochairmen, Jay Lieske, for pointing out to me that so simple and direct a comparison is wrong in principle and actually underestimates the quality of Otto Vassilyevich's result. When allowance is made for the different epochs and different time units (tropical and Julian centuries) used, the two values are within 0.02 percent. If Peters' 1844 revision is used, the agreement is even better. If present indications from VLBI results that the I.A.U. 1976 value is too high are confirmed, the agreement between the result obtained by Struve and Peters and the best available modern value is almost perfect. That is a measure of the quality of work in Pulkovo: 150 years ago the astronomers here could achieve the same accuracy that our best modern technology can provide. The characteristics of the solar motion were nothing like so well determined; partly because the still limited knowledge of stellar distances led Otto Vassilyevich to an erroneous estimate of the Sun's linear speed and partly because, as he showed himself, determination of the direction of solar motion is very sensitive to quite small systematic errors in the first-epoch observations. Even Bradley's excellent data could not be assumed to be free from such errors. It was indeed the analysis of errors in the memoir on precession that particularly impressed Airy and probably played a role in the decision to award the Gold Medal to Otto Vassilyevich.

Excellent though the determination of the coefficient of precession was, it never quite attained the status of the elder Struve's work on aberration. Newcomb (1895) referred to Otto Vassilyevich's work on precession (and also to Bessel's) as "classic", but he actually favoured the result derived by one of Otto's two astronomer sons, Ludwig (Struve 1887). Perhaps he assumed that the longer timebase available to Ludwig would guarantee the greater reliability of the result. From our perspective, it seems that no improvement was necessary to the earlier value.

\section{International cooperation}

Astronomy depends on international cooperation even more than do other branches of science; and the field of astronomy that we have come here to discuss perhaps needs international cooperation most of all. For Vassily Yakovlevich, cooperation was mainly informal, through his personal 
friendships; although the geodetic work of his early career gave him many official contacts, too. Prominent amongst his personal friends were, of course, F.W. Bessel in Germany, G.B. Airy in England and U.J.J. Le Verrier in France. International meetings were much rarer then than now, but Vassily Yakovlevich had a wide freedom to travel and the opportunities this gave him to maintain and to expand his circle of friends undoubtedly contributed to the success with which he enriched the reputation of Russian science.

Otto Vassilyevich inherited many of his father's friends, particularly Le Verrier and Airy, with whom he remained on excellent terms until they each in turn died. Later he made his own friends, of whom the outstanding ones were David Gill in South Africa and Simon Newcomb in Washington. Such informal contacts remained important throughout his life, but the more formal kind of meeting, to which we are accustomed, began to be important too. Thus Otto Vassilyevich was active both in the Astronomische Gesellschaft and the Carte $\mathrm{du}$ Ciel, the first major organized international project in astronomy.

A few observatories thoughout the world are distinguished from all others by the combination of the length and the quality of their traditions. We might differ about just how many there are, but I think we would all include Paris, Greenwich, the Cape of Good Hope, the U.S. Naval Observatory and, of course, our host Observatory of Pulkovo, even though one of these no longer exists as a separate entity and another is undergoing radical change. I think we shall hear more about these observatories from Steven Dick (1989); I wish only to point out that the web of personal friendships constructed by the two Struves, connected Pulkovo with each of the other major observatories of their time. This, again, enriched the science of their homeland.

\section{Epilogue}

As I began by trying to recreate a scene from the lives of Vassily Yakovlevich and his son, permit me to close by entertaining the thought that they are with us in spirit today and, unseen and unheard by us, they can watch what we do and listen to what we say. How would they react? Astronomy has been transformed since their deaths, although perhaps Vassily Yakovlevich foresaw a few faint hints of what was to come when he wrote Etudes d'astronomie stellaire (Struve 1847). They would, I am sure, be gratified that we are still concerned with the problems to which they devoted so much effort; they would be amazed and excited at the prospect of making astrometric observations from above the Earth's atmosphere. They would be thankful that their great observatory has risen, phoenix-like, from the ashes to which it was reduced, soon after its first century, by a grim and horrible struggle. They would be flattered that we still speak of them and their work. If they could, they would certainly come and greet us each by name, as they did their guests of 125 years ago. I venture to suggest, however, that one of the things that would give them most pleasure would be that we have seen fit to celebrate this jubilee with a meeting sponsored by the International Astronomical Union - a body that realizes, however, imperfectly, the vital international cooperation that is as much a part of the Struves' legacy to us as was their scientific work. Although even Otto Vassilyevich died well before there was an I.A.U., his other astronomer son, Hermann, was active in the precursor International Union for Cooperation in Solar Research, and his grandson and namesake, the second Otto Struve, was one of our Presidents. Within the I.A.U., each one of us here has built a web of personal friendships of his or her own, and many of us are rightly proud of such friendships maintained across the barriers of language, culture and different ideas of political and economic justice, even at times 
of tension in the world. That pride is justified, because friendships of that kind are in the best tradition of the Struves, of Pulkovo Observatory and of science.

I dedicate this paper to the memory of a great-grandson of Vassily Yakovlevich Struve, Dr. Nils Lindhagen, who died earlier this year. In his home in Sweden, I dined with cutlery engraved with the initials "W.S." and I drank wine from glasses owned and used in Pulkovo by Magnus Nyrén. Lindhagen's enthusiasm and practical help did much to ensure whatever success my biography of his ancestors may enjoy and is, therefore, directly responsible for my having been invited to speak at this symposium.

\section{References}

Abbe, C. 1867, Dorpat and Pulkovo, Report of the Smithsonian Institute, Appendix, p.370.

Airy, G.B. 1848, Astron. Nachr. 26, 353.

Airy, G.B. 1850, Mem. Roy. Astron. Soc. 19, 271.

Astronomical Almanac 1989, U.S. Government Printing Office and Her Majesty's Stationery Office.

Batten, A.H. 1988, Resolute and Undertaking Characters: The Lives of Wilhelm and Otto Struve. D. Reidel, Dordrecht, The Netherlands.

Campbell, B. 1983, Publ. Astron. Soc. Pacific 95, 977.

Chandler, S.C. 1891a, Astron.J. 11, 59.

Chandler, S.C. 1891b, Astron.J. 11, 65.

Chandler, S.C. 1891c, Astron.J. 11, 83.

Chandler, S.C. 1893a, Astron.J. 13, 57.

Chandler, S.C. 1893b, Astron.J. 13, 65.

Dick, S. 1989, this symposium.

Holden, E.S. (editor) 1897, Memoirs of W.C. and G.P. Bond, C.A. Murdock and Co., San Francisco and Lemke and Buechner, New York City. Reprinted 1980 Arno Press, New York. p.100.

Newcomb, S. 1895, The Elements of the Four Inner Planets and the Fundamental Constants of Astronomy, Government Printing Office, Washington, U.S.A.

Nyrén, M. 1883, Mém. de l'Acad. Impériale des Sciences de Saint-Pétersbourg, 7ème série, 31, No. 9, p.47.

Peters, C.A.F. 1844, Mém. de l'Acad. Imperiale des Sciences de Saint-Pétersbourg, 6ème série, 3, p.125.

Struve, F.G.W. (V.Ya.) 1826, Mem. Roy. Astron. Soc. $2,93$.

Struve, F.G.W. 1843a, Mém. de l'Acad. Impériale des Sciences de Saint-Pétersbourg, 6ème série, 3, p.229.

Struve, F.G.W. 1843b, Astron. Nachr. 21, 57.

Struve, F.G.W. 1845, Description de l' observatoire astronomique centrale de Poulkova, Imprimerie de l'académie impériale des sciences, Saint-Pétersbourg.

Struve, F.G.W. 1847, Etudes d'astronomie stellaire, Imprimerie de l'académie impériale des sciences, Saint-Pétersbourg.

Struve, L. 1887, Mém. de l' Acad. Impériale des Sciences de Saint-Pétersbourg, 7ème série, 35, No.3.

Struve, N. 1915, Deutsche Monatschrift für Russland, 57.

Struve, O.W. (O.V.) 1841, Mém. de l'Acad. Impériale des Sciences de Saint-Pétersbourg, 6ème série, 3.

Wood, F.B. 1989, in Algols, (ed. A.H. Batten, Space Science Reviews 50), Kluwer, Dordrecht, p. xix. 